\title{
NAMBAN KOFFER
}

Op de TEFAF van dit jaar heeft het Rijksmuseum een Japanse koffer gekocht uit de periode rond 1600. De koffer is bedekt met zwarte lak en daarop zijn in panelen voorstellingen geschilderd in goudlak. De panelen bevatten aan de voorzijde en de voorzijde van het deksel dieren - deels in paren - en in één geval een kar tussen de bomen en struiken. De zijkanten en de achterkant van de koffer zijn eenvoudiger: aan de zijkant twee smalle velden met dezelfde weelderige bomen en aan de achterkant drie velden met meer gestileerde en wijder opgezette ranken. Een deel van de bomen is herkenbaar als esdoorns, die vanwege hun kleurenpracht in dat jaargetijde, symbool staan voor de herfst. Ook het paar herten vormt een element waarmee naar dat jaargetijde wordt verwezen. De binnenkant van de koffer is effen zwart met daarop - zonder kaders - een voorstelling van kraanvogels en rijstschoven die te drogen hangen, en ook dit is een motief dat de herfst aanduidt. De decors aan de buitenzijde zijn verrijkt met inlegwerk van parelmoer en dit parelmoer komt in veel grotere hoeveelheden terug in de decoratieve randen die de panelen omgeven. Dit type lakwerk met de spontane schilderstijl en het inlegwerk van parelmoer wordt Namban-lakwerk genoemd. Met Namban werden de Zuidelijke barbaren aangeduid, waarmee de Japanners alle buitenlanders behalve de Chinezen en Koreanen bedoelden. In de $16^{\mathrm{e}}$ eeuw waren dit vooral de Portugezen, die vanaf 1542 of 1543 handel dreven in Japan. Het was dus een product dat exclusief voor Europeanen werd gemaakt en de vorm gaat dan ook volledig terug op Europese kisten die als voorbeeld hebben gediend. De parelmoeren banden tussen de panelen verwijzen naar het ijzeren beslag dat op deze kisten was aangebracht.

\section{De handel in lakwerk}

De Portugese importen van Aziatische voorwerpen waren exclusiever dan de latere Nederlandse importen. Chinees porselein, Japans lakwerk en kostbaarheden uit India bereikten Europa in kleine hoeveelheden en circuleerden daar met name in de hofkringen, die nauw verbonden waren met de Portugese overzeese handel. Een kabinet van Namban-lakwerk afkomstig uit de Kunstkammer van Schloss Ambras is een voorbeeld van een dergelijk stuk lakwerk dat al in de $16^{\mathfrak{e}}$ eeuw in een vorstelijke collectie belandde.

Nederlandse handelaren waren aan het eind van de $16^{\mathrm{e}}$ eeuw vastbesloten zelf naar Indië te varen om daar handel te drijven. Enerzijds waren ook in Nederland de exotische schatten bekend die de Portugezen aanvoerden, anderzijds hoorden zij van de grote winsten die de Portugezen behaalden met de handel in Azië zelf. Voor het Rijksmuseum is de Namban-koffer van grote betekenis omdat het de collectie ontbrak aan een groot en aansprekend stuk lakwerk, dat direct verbonden is met de periode dat de Nederlandse handel : $37 \mathrm{Am}$ met Azië op gang kwam. Of de koffer door Portugezen naar Europa' is free access 
verscheept (en dus behoorde tot de kunstschatten die mede de aanleiding vormden voor de Nederlandse handel op Azië) of op een van de eerste Nederlandse schepen naar Nederland is gekomen, is niet bekend en ook niet

Afbeelding 2 Detail van de decoratie van groot belang. Wel is zeker dat de Nederlanders dergelijke koffers importeerden. De handelscontacten tussen Nederland en Japan werden jaarlijks met geschenken over en weer bezegeld en de 'Japonsche rokken' die de Nederlanders ten geschenke ontvingen, werden - zo blijkt uit vermeldingen in het VOC-archief - in lakwerken koffers vervoerd. In de eerste decennia van de $17^{e}$ eeuw kan met deze aanduiding niets anders bedoeld zijn dan Namban-lakwerk.

\section{De belangstelling voor lakwerk}

De Oranjes hadden grote interesse voor kunstnijverheidsproducten uit China en Japan. Hun voorliefde heeft de belangstelling voor porselein en lakwerk in het algemeen sterk gestimuleerd. Het lakkabinet, een kleine kamer waarbij de wanden zijn betimmerd met lakpanelen afkomstig uit kisten en koffers, is een Nederlandse inventie. Amalia van Solms, echtgenote van Frederik Hendrik, liet in 1654 in Den Haag het eerste lakkabinet maken. Ongetwijfeld - het kabinet bestaat niet meer - was hieronder Namban-lakwerk. Hoe hoog een dergelijke koffer werd gewaardeerd, blijkt wel uit een geschenk uit 1616. In dat jaar schonken de Staten-Generaal aan de koning van Zweden een koffer die in vorm, formaat en decoratietechniek grote overeenkomst vertoont met de nieuw verworven koffer van het Rijksmuseum; alleen de indeling van de velden en de motieven verschillen.

Dergelijke koffers werden in uiteenlopende maten gemaakt. Soms was sprake van een set van koffers met een identieke decoratie in oplopende formaten. In de Koninklijke Collectie in Denemarken bevindt zich zo'n - iets latere serie. Ook de aanwinst van het Rijksmuseum maakte waarschijnlijk deel uit van een dergelijke serie. Een groter formaat, met naast elkaar vier velden, werd recent verhandeld in Parijs. De huidige verblijfplaats is onbekend. De kleinste koffertjes hebben een breedte van $15 \mathrm{a} 20 \mathrm{~cm}$. Zij hebben natuurlijk een geheel andere uitstraling dan de grote exemplaren. De decoratie op deze kleine stukken met ingenieus vervlochten motieven verschilt vaak ook enigszins van de beschildering op de grote stukken. Deze kleine koffertjes zijn in het begin van de $17^{\mathrm{e}}$ eeuw een directe inspiratie geweest voor het werk van de Nederlandse lakwerker Kick, waarvan recent ook een stuk is verworven (zie de bijdrage van Femke Diercks). De Staten-Generaal bestelden ook bij Willem Kick lakwerk voor diplomatieke geschenken. Dat Namban-lakwerk zo snel werd geïmiteerd en voor dergelijke geschenken geschikt werden geacht, kan eveneens gelden als een indicatie voor de hoge waardering van Nambanlakwerk in het begin van de $17^{\mathrm{e}}$ eeuw. 


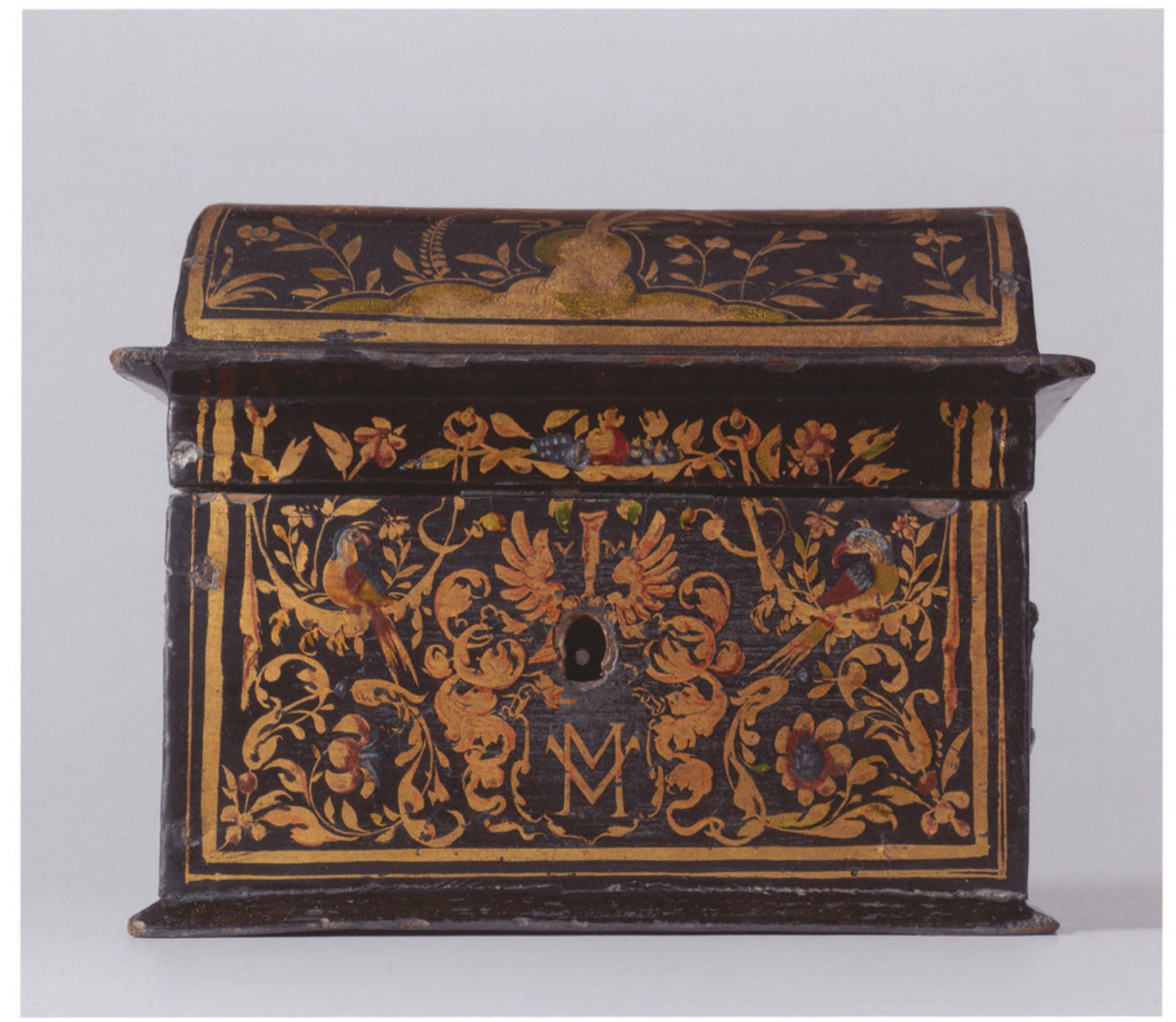

\section{Afbeelding 1}

Toegeschreven aan

Willem Kick, kistje,

gelakt eikenhout,

hoogte $12 \mathrm{~cm}$., breedte

$15,4 \mathrm{~cm}$., Amsterdam,

1618, Rijksmuseum,

BK-2007-6 